WSRC-TR-2003-00546

Revision 0

\title{
Preparation and Use of Dried Monosodium Titanate
}

D. T. Hobbs, Savannah River Technology Center

M. D. Nyman, Sandia National Laboratory

Westinghouse Savannah River Company

Savannah River Site

Aiken, SC 29808

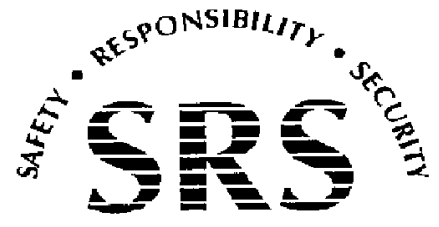

SAVANNAH RIVER SITE

PREPARED FOR THE U.S. DEPARTMENT OF ENERGY UNDER CONTRACT NO. DE-AC09-96SR18500 
This document was prepared in conjunction with work accomplished under Contract No. DE-AC09-96SR18500 with the U. S. Department of Energy.

\section{DISCLAIMER}

This report was prepared as an account of work sponsored by an agency of the United States Government. Neither the United States Government nor any agency thereof, nor any of their employees, makes any warranty, express or implied, or assumes any legal liability or responsibility for the accuracy, completeness, or usefulness of any information, apparatus, product or process disclosed, or represents that its use would not infringe privately owned rights. Reference herein to any specific commercial product, process or service by trade name, trademark, manufacturer, or otherwise does not necessarily constitute or imply its endorsement, recommendation, or favoring by the United States Government or any agency thereof. The views and opinions of authors expressed herein do not necessarily state or reflect those of the United States Government or any agency thereof.

This report has been reproduced directly from the best available copy.

Available for sale to the public, in paper, from: U.S. Department of Commerce, National Technical Information Service, 5285 Port Royal Road, Springfield, VA 22161, phone: (800) 553-6847, fax: (703) 605-6900

email: orders@ntis.fedworld.gov

online ordering: http://www.ntis.gov/help/index.asp

Available electronically at http://www.osti.gov/bridge

Available for a processing fee to U.S. Department of Energy and its contractors, in paper, from: U.S. Department of Energy, Office of Scientific and Technical Information, P.O. Box 62, Oak Ridge, TN 37831-0062,

phone: (865)576-8401,

fax: (865)576-5728

email: $\underline{\text { reports@ adonis.osti.gov }}$ 


\subsection{Summary}

Savannah River site experience with handling dry solids indicates that handling dried MST within the SWPF or ARP is feasible and could offer certain advantages if the dried material performed equivalently. This evaluation did not identify an operational reason that overwhelmingly supports introducing MST into the SWPF in either a slurry or dry chemical form. Current configuration of the ARP limits introduction of the MST only as a slurry form into the Alpha Sorption Tank. However, testing indicates that dried MST exhibits poorer strontium and alpha removal kinetics, which may adversely impact process cycle times and waste feed throughput. Thus, we recommend that these facilities not use dried MST.

\subsection{Introduction}

MST is an inorganic sorbent material that exhibits high selectivity for strontium and actinide elements in the presence of strongly alkaline and high sodium containing salt solutions. $^{1,2}$ The Savannah River Site (SRS) selected this material for strontium and plutonium removal from high-level waste solutions in the early 1980s as part of the InTank Precipitation process. ${ }^{3}$ In 2000, the Department of Energy (DOE) selected MST for the strontium/actinide separation step within the SWPF. ${ }^{4}$ Subsequently, Salt Processing Program Engineering selected MST for use in the Actinide Removal Process (ARP) to treat low-curie waste solutions in a small treatment facility located in $512-\mathrm{S}^{5}$

Original development of MST at Sandia National Laboratory (SNL) produced a dried powder. Unpublished studies conducted by L. L. Kipatrick and D. T. Hobbs during the 1980 s indicated that air drying of the MST at elevated temperature $\left(\geq 100^{\circ} \mathrm{C}\right)$ adversely impacted strontium removal performance. Principally due to the poorer sorption characteristics of MST dried at elevated temperature, procurement of MST at SRS for the In-Tank Precipitation (ITP) process specified that the vendor prepare and isolate the material without drying and deliver the MST to the Westinghouse Savannah River Company (WSRC) as an aqueous solution containing 10 - 20 wt\% MST solids. ${ }^{6}$

Handling the MST as a dry powder may have certain advantages over an aqueous slurry in processing facilities. Advantages include having more precise control of MST quantity, potentially longer chemical shelf-life and no possibility of a chemical spill from a leaking storage container. The principal disadvantage of dry chemicals is the equipment needed to control dusts associated with transferring solids. Advantages of the slurry form of MST include previous onsite experience, easy transfer of material from storage to processing areas and no additional equipment needed for slurry makeup and dust collection. Disadvantages of a MST slurry include less precise control of MST additions, possibility of a chemical spill from a leak in the storage containers and transfer lines and additional equipment needed to suspend or maintain suspension of MST solids in the slurry.

This report assesses the feasibility of handling MST in the SWPF and ARP facility as a dry solid versus that as an aqueous slurry. In addition to this assessment, we tested the effects of drying on MST properties including strontium and actinide removal performance. This work represents two of the subtasks identified in the scope of work 
for the DOE funded project to develop improved sorbent materials for strontium/actinide separations at $\mathrm{SRS}^{7}$

\subsection{Results and Discussion}

3.1 Handling of Dried Sorbent Materials in Processing Facilities

Dry chemicals are used in a number of waste management processes at the SRS including the Saltstone facility and Defense Waste Processing Facility (DWPF). The Saltstone facility handles three dry chemicals, cement, flyash and slag, which are ingredients in the cement-based wasteform used to encapsulate decontaminated and low-level waste solutions at the SRS. The DWPF handles powdered glass frit in two separate operations, (1) makeup of glass frit slurry for feed to the Slurry Mix Evaporator (SME) and (2) make up glass frit slurry used to decontaminate the exterior of the stainless steel glass canister. The DWPF also prepares relatively small solutions of various chemicals by measuring the weight of a dry chemical and adding it to a known amount of water.

The particle size of the dry chemicals used at Saltstone is small ranging from approximately 1 to 100 microns, which is very similar to that of MST (1- 35 microns). Thus, solids handling issues related to particle size of solids with Saltstone dry chemicals (e.g., dusting) mirrors that of dried MST. Saltstone facility operations handle these dry chemicals in very large quantities, which are much larger than that planned at either the ARP or the SWPF.

The Saltstone facility introduces the dry chemicals as solids and not as an aqueous slurry into the radioactive processing area, i.e., the grout mixer. Dry chemicals used to prepare grout at Saltstone are stored in separate silos. Solids transfer pneumatically from the silos into weigh hoppers and then into blending bins. From the blending bins the solids transfer into a premix feed bin. From this bin the solids transfer to a weigh hopper and then into the mixer vessel where it mixes with decontaminated salt solution. All solids handling systems feature active and passive equipment to capture and prevent the release of dusts that could be inhaled by personnel.

Unlike Saltstone, DWPF does not introduce dry solids directly into the radioactive processing area. Glass frit transfers into a slurry makeup system, which then transfers the frit slurry into the radioactive processing area. Frit slurry prepared for the SME occurs in the Frit Handling and Makeup System to produce a suspension of known solids content. In this system, located in a clean area, solid glass frit is weighed out and mixed with a known quantity of dilute formic acid solution in a clean area of the facility. The Process Frit Slurry Feed System transfers the suspension from the makeup tank to the Slurry Mix Evaporator (SME) which is located in the radioactive operations area of the facility. Makeup of frit slurry for canister decontamination occurs in the Decontamination Frit Slurry Feed Tank, which is also in a clean area. Operators then pump the frit slurry into the Canister Decontamination Chamber. Both the SME Frit Handling and Makeup System and the Decontamination Frit Slurry Feed Tank feature recirculation systems to keep the grass frit well suspended. 
The particle size specification of the glass frit provides for the bulk of the solids to range between 74 and 177 microns. This specification allows up to 10\%<74 microns and 2\% greater than 177 microns. Thus, from a particle size perspective, MST solids are much finer than the glass frit used in the DWPF. The quantity of glass frit used in DWPF is more similar to that planned for MST (on a dry solids basis) at the ARP and the SWPF as compared to that for the dry chemicals used at the Saltstone facility.

Equipment used for dry chemicals handling in both facilities use active and passive systems to protect personnel from inhalation of the solids. This equipment features commercially-available filter systems to prevent release of dusts that serve as an inhalation hazard to workers in the area. Cognizant engineers in both facilities indicated no unusual problems associated with this type of equipment. Given the similarity in particle size of the MST and the dry chemicals used in the Saltstone facility, off-the-shelf equipment should prove sufficient for handling dried MST solids in either the SWPF or ARP facility. The chemical composition and chemical or physical properties of the MST $\left(\mathrm{NaTi}_{2} \mathrm{O}_{5} \mathrm{H}\right)$ does not require the use of special materials in the fabrication of the filter equipment.

Tables 1 and 2 provide a summary of advantages and disadvantages identified for handling MST as either as a slurry or a dry solid. One advantage of handling MST as a dry chemical in the SWPF and the ARP facility is providing a more accurate quantity of MST per processing batch. Vendor-supplied MST slurry will have a greater uncertainty about the quantity of MST added due to errors associated with obtaining and analyzing the slurry for MST content and homogeneously suspending the MST for transferring the desired quantity of the homogeneous suspension. The latter error is minimized if a single unit (e.g., pail or drum) of MST slurry serves as the batch quantity. This is the situation planned for the ARP facility. MST procured for the ARP facility will be packaged in 5gallon pails such that two pails will provide the quantity of MST needed per batch of waste processed. If waste characterization indicates that a batch of waste requires a higher quantity of MST, then additional pails of MST slurry will be added.

MST addition at the ARP facility occurs at an entry point located outside of 512-S in the cold feeds area. This entry point requires addition of the MST as a slurry. Addition of MST as a dry solid to the Alpha Sorption Tank in 512-S would require the installation of new equipment for pneumatic handling of dry MST both outside and inside of 512-S. The expense of installing new equipment within the shielded cell and limited access to the processing tank makes this alternative unattractive.

If MST addition requires more accurate quantities or feed batch variability offers significant variance in the quantity of MST needed, the facility can contract with a vendor to supply MST as a dry solid. Equipment could be installed at 512-S relatively easily to allow the facility to prepare the MST slurry at the desired quantity and concentration. In practice batch variability should prove small given that the feed solution to 512-S will come from a staging tank such as Tank $49 \mathrm{H}$, which has slurry pumps for mixing and will contain several hundred thousand gallons of feed solution that will have been characterized prior to feeding to the ARP facility. 
Table 1. Advantages and Impacts of Handling MST in Dry and Slurry Forms

Form
MST Slurry

Dry MST

\section{Advantage}

previous onsite experience

with handling this form of MST

easily transferred from storage

to processing area

no dust collection or slurry

makeup equipment required

more precise control of MST

quantity

potential longer chemical

shelf-life

no possibility of spills

lower transportation costs

smaller storage footprint

\section{Impact}

decreased training costs

no special equipment required

reduced capital and operating costs

reduce use of excess MST; less downstream impact on DWPF

eliminate need to discard or rework batch of MST

eliminate spill cleanup costs

decrease operating costs

decrease operating costs

Table 2. Disadvantages and Impacts of Handling MST in Dry and Slurry Forms

Form

MST Slurry

Dry MST
Disadvantage

possibility of spill during storage

requires equipment to suspend

or maintain suspension

less precise control of MST

additions in process batch

requires dust control equipment

requires equipment to deliver dry solid to process equipment or slurry makeup equipment

potentially higher manufacturing cost

\section{Impact}

incur costs to cleanup spill

higher capital and operating

costs

increased use of MST to ensure satisfactory quantity; increased $\mathrm{TiO}_{2}$ sent to DWPF

increased capital and operating costs

increased capital and operating costs

increased operating cost 
Batch usage of MST will be much greater in the SWPF compared to that in the ARP facility. The quantity of MST will vary proportionately to the size of the Alpha Sorption Tank and the process concentration of MST (e.g., $0.4 \mathrm{~g}$ MST/L). Estimated quantities of MST required in the SWPF range from about 50 to $400 \mathrm{~kg}$ per batch, which is between 10 and 80 times that planned for the ARP facility. The requisite volume of MST slurry needed for the SWPF is similar to the glass frit slurry used in the DWPF Canister Decontamination Chamber.

Given this relatively low solids usage, installation of a solids handling system for introducing dry MST solids directly into the Alpha Sorption Tank appears less cost effective. Procurement of MST as a slurry decreases equipment usage from a slurry makeup perspective. However, cold chemicals storage equipment will be larger to accommodate the higher slurry volume compared to the dry solids volume. MST slurry makeup equipment would be similar is size to that used for Decontamination Frit Slurry in the DWPF.

As discussed earlier, makeup of MST slurry in SWPF would allow more flexibility and control and potentially less variance in MST additions to the Alpha Sorption Tank. Storage of a dry solid would also eliminate the possibility of liquid spill in the cold chemical storage area. Thus, there are valid reasons for handling MST as a dry chemical in the SWPF.

Another disadvantage of a dry MST material is the possibility of a higher manufacturing cost, which results in increased operating costs for the ARP and SWPF. The higher chemical cost results from the additional production step required to dry the MST. The increased manufacturing cost is reduced somewhat by a lower cost of shipping resulting from reduced weight of the dry MST compared to that of the MST slurry. We estimate that drying the MST would add no more than 25\% to the cost of the MST.

Introducing MST as a slurry or a dry solid has advantages and disadvantages. We did not identify any single reason to exclude either method from consideration for use in the SWPF. Thus we conclude that MST can be introduced into the SWPF on an operational basis as either an aqueous slurry or dry solid. We recommend that a more detailed cost evaluation be considered for the SWPF should the Sr/actinide removal characteristics of both MST forms prove similar.

\subsection{Effects of Drying on MST Characteristics}

3.2.1. Experimental Methods

All testing featured MST prepared by the Optima Chemical Company and identified as Batch \#00-QAB-417. Initial drying tests dried the as-received MST slurry and as received MST after filtration and washing with three $30-\mathrm{mL}$ portions of deionized water to remove soluble salts to air dry at ambient temperature. Subsequent MST drying experiments consisted of filtering approximately $3.3 \mathrm{~g}$ (targeting $0.5 \mathrm{~g}$ of dried solid) of the MST slurry through a Buchner filter funnel, washing the moist solids five times with 30-ml of deionized water taking care not to allow the MST solids to dry out between washes and transferring the washed moist solids quickly to a preheated oven or vacuum 
oven and drying for 4 hours. Six samples were prepared in this manner with oven temperatures set at 55,75 , and $100{ }^{\circ} \mathrm{C}$ and either at atmospheric pressure or at reduced pressure (0.02 atm). After drying for 4 hours, we cooled the dried MST samples to ambient laboratory temperature in a dessicator and stored in tightly stoppered glass vials.

Initial characterization of the dried MST samples featured scanning electron microscopy (SEM), thermogravimetric analysis (TGA), X-ray diffraction (XRD) and determination of the strontium decontamination factor at the Sandia National Laboratory (SNL). This testing featured either a $0.5 \mathrm{mg} / \mathrm{L}$ solution of strontium in water or a simulated waste solution having the salt concentration listed in Table 3 and spiked with ${ }^{85} \mathrm{Sr}$ radiotracer.

Table 3. Simulated Waste Solution Composition

\begin{tabular}{cc} 
Component & Concentration \\
\cline { 2 - 3 } $\mathrm{NaNO}_{3}$ & $2.50 \mathrm{M}$ \\
$\mathrm{NaOH}$ & $1.33 \mathrm{M}$ \\
$\mathrm{Na}_{2} \mathrm{SO}_{4}$ & $0.521 \mathrm{M}$ \\
$\mathrm{NaAl}(\mathrm{OH})_{4}$ & $0.429 \mathrm{M}$ \\
$\mathrm{NaNO}_{2}$ & $0.134 \mathrm{M}$ \\
$\mathrm{Na}_{2} \mathrm{CO}_{3}$ & $0.0260 \mathrm{M}$ \\
$\mathrm{Total} \mathrm{Na}_{\mathrm{U}}$ & $5.6 \mathrm{M}$ \\
$\mathrm{U}$ & $10 \mathrm{mg} / \mathrm{L}$ \\
$\mathrm{Pu}$ & $0.2 \mathrm{mg} / \mathrm{L}$ \\
$\mathrm{Np}$ & $0.5 \mathrm{mg} / \mathrm{L}$ \\
$\mathrm{Sr}$ & $0.3 \mathrm{mg} / \mathrm{L}$
\end{tabular}

Testing of combined strontium and actinide removal performance occurred at the Savannah River Technology Center (SRTC) using the same simulated waste solution composition as shown in Table 3 including plutonium, uranium, and neptunium in addition to ${ }^{85} \mathrm{Sr}$. Strontium and actinide removal testing occurred at $25 \pm 2{ }^{\circ} \mathrm{C}$ at a MST solids concentration of $0.4 \mathrm{~g} / \mathrm{L}$. Sampling of the test bottles occurred at 4, 24 and 168 hours of contact. We filtered the samples through 0.45-micron syringe filters (nylon membrane) to remove MST filters. Gamma spectroscopy measured the ${ }^{85} \mathrm{Sr}$, neptunium and americium content while alpha spectroscopy measured the alpha content in the isolated filtrates.

\subsubsection{Characteristics and Performance Testing of Dried MST}

Initally we dried the MST slurry (Optima Batch \#00-QAB-417) at room temperature asreceived and after washing with deionized water to remove soluble salts. The batch of MST slurry used in this testing contains $15 \mathrm{wt} \%$ MST in an aqueous solution of $0.1 \mathrm{M}$ $\mathrm{NaNO}_{2}$ and $0.1 \mathrm{M} \mathrm{NaOH}$. The sodium hydroxide and sodium nitrite are added to the MST slurry as corrosion inhibitors. After drying we analyzed the dry solids by scanning electron microscopy (SEM) to determine particle morphology. 
Figure 1A shows an SEM image of MST solids obtained by filtering the slurry using a Buchner funnel with filter paper, rinsing the MST powder with deionized water and letting it air dry at room temperature on the filter paper. Figure 1B shows MST solids obtained by evaporation of the water (and thus leaving the $\mathrm{NaOH}$ and $\mathrm{NaNO}_{2}$ salts to deposit on the MST solids. In the latter case, the morphology of micron-sized spheres is preserved. In the former case, the morphology changes by agglomeration of the micron-
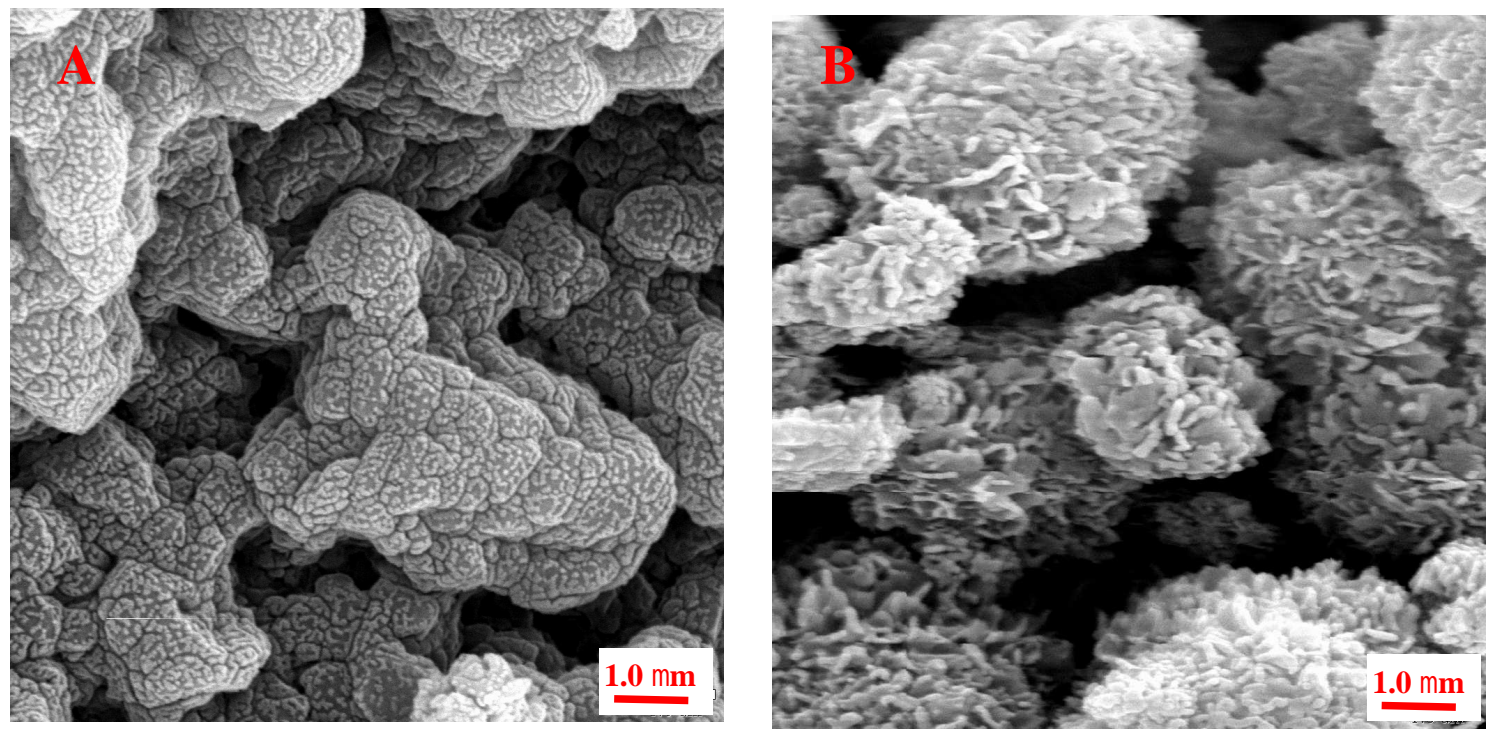

Figure 1. SEM images of MST from slurry (Batch \#00-QAB-417). A. Prepared by filtering and washing, drying at room temperature, and mounting dry powder on SEM carbon disc.

B. Prepared by dropping slurry on SEM carbon disc and allowing solvent to evaporate.

sized particles. We do not know why this subtle difference in treatment results in a vastly different morphology. We speculate that the surface charge of the MST particles is more negative in the as-received slurry due to the higher solution $\mathrm{pH}$ compared to the washed material resulting in greater repulsion between individual particles.

We suspect that preservation of the spherical, porous-surface morphology of the MST such as that exhibited in Figure 1 is important for retaining the superior sorption performance since this allows greater available surface area for sorption. Conversely, evaporating the water from the as-received MST slurry with corrosion inhibitors may not be desirable as the deposited salts, if not easily hydrated when added to waste, may adversely impact sorption and mass transfer. Furthermore, addition of corrosion inhibitors before drying adds production costs to the MST. Thus, we investigated alternative options for drying the MST without corrosion inhibitors present in solution while preserving the spherical morphology.

Alternative drying conditions featured rinsing the MST solids free of soluble salts and drying the moist MST solids at elevated temperature $\left(55,75\right.$ and $\left.100{ }^{\circ} \mathrm{C}\right)$ either at atmospheric pressure or at reduced pressure $(0.007 \mathrm{~atm})$ for 4 hours. After drying we analyzed the dried solids to determine particle morphology, thermogravimetric properties, crystallinity as well as strontium and actinide removal performance. 
SEM analyses indicated that the spherical particle morphology persisted for all of the salt-free samples dried at elevated temperature at atmospheric or reduced pressure (see Figure 2). Characterization by thermogravimetric analysis (TGA), as depicted in Figure 3 , provides insight to the nature of water present in the MST. For the filtered and washed MST we observe the greatest weight loss $(\sim 23 \mathrm{wt} \%)$. For the samples dried at elevated temperatures, we observe weight losses between about 10 and $15 \mathrm{wt} \%$. Increased temperature of drying resulted in increased water removal and lower weight loss in the TGA measurements. We attribute the higher weight loss from the filtered as-received sample, after filtering and washing, to the removal of both bound and unbound water. Unbound water would be that water that resides between particles, on particle surfaces and in pores. Bound water is that which resides within the structural lattice of the MST. Note that weight loss occurs in the filtered MST sample at lower temperature than those dried at elevated temperature. We attribute this feature to the removal of unbound water residing in the particle surfaces and pores. From the shapes of the curves and onset of weight loss, the MST samples dried at elevated temperatures appear to have very little unbound water remaining. 

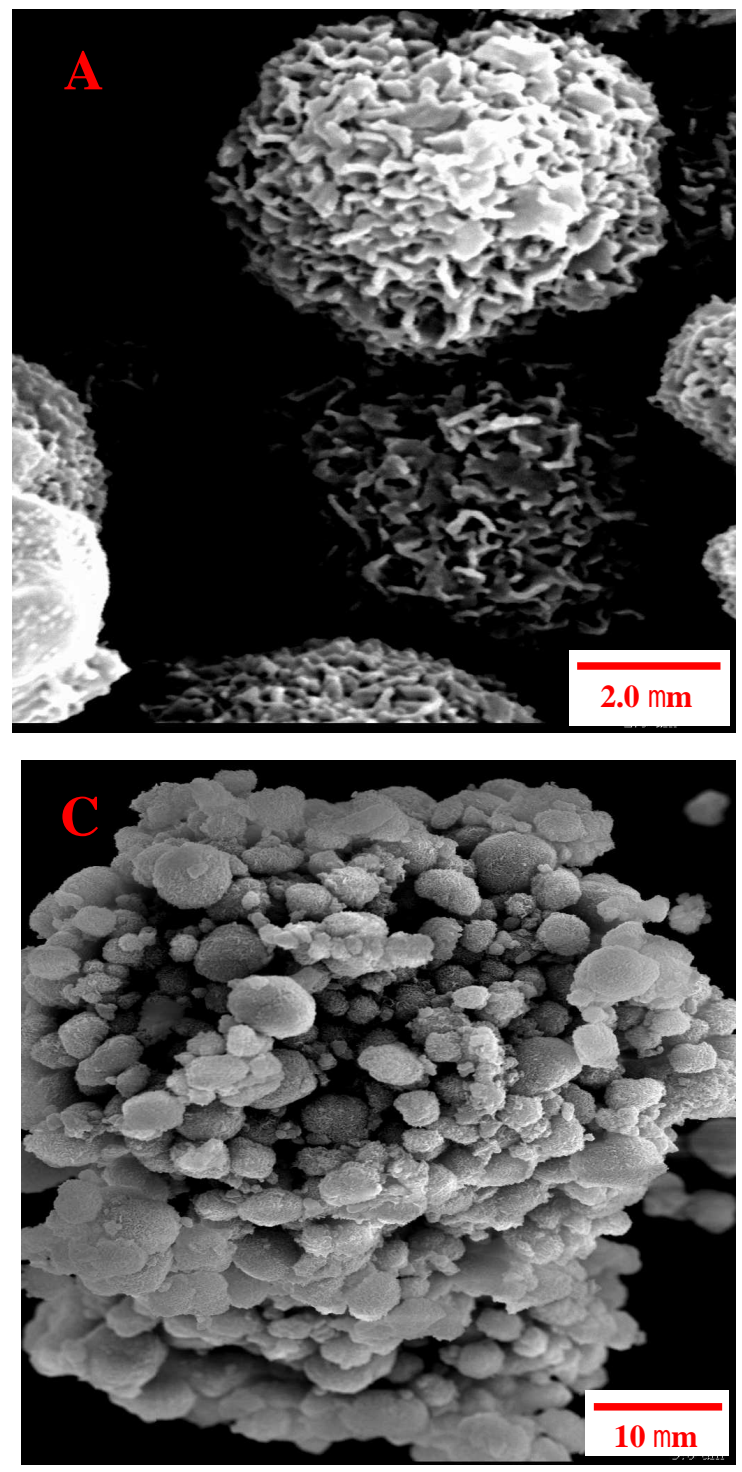

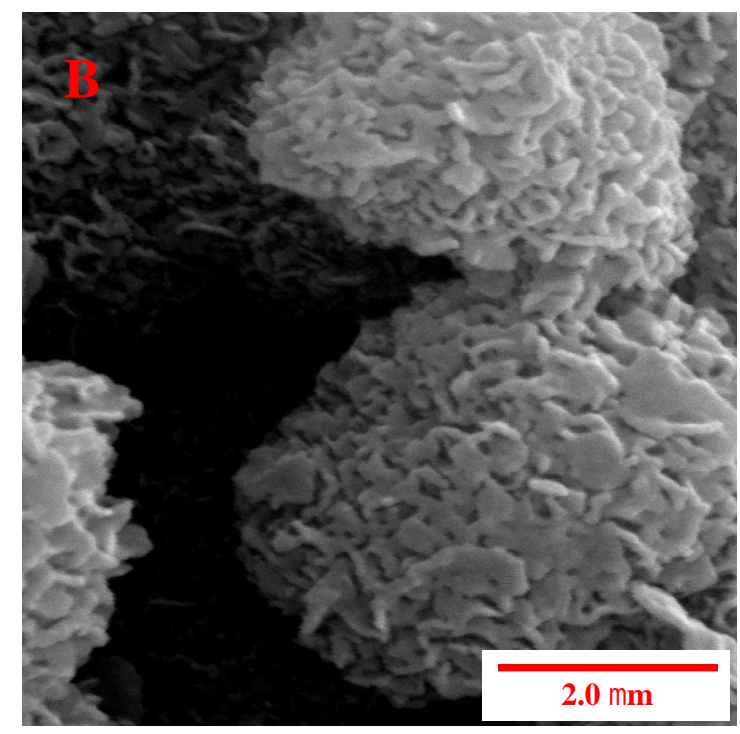

Figure 2. SEM images of MST dried at $55^{\circ} \mathrm{C}$ with no vacuum (A),

$100{ }^{\circ} \mathrm{C}$ under vacuum (B), and $100{ }^{\circ} \mathrm{C}$ under vacuum at lower magnification $(\mathbf{C})$ 
Figure 3. Thermogravimeteric Analysis of Dried MST Samples

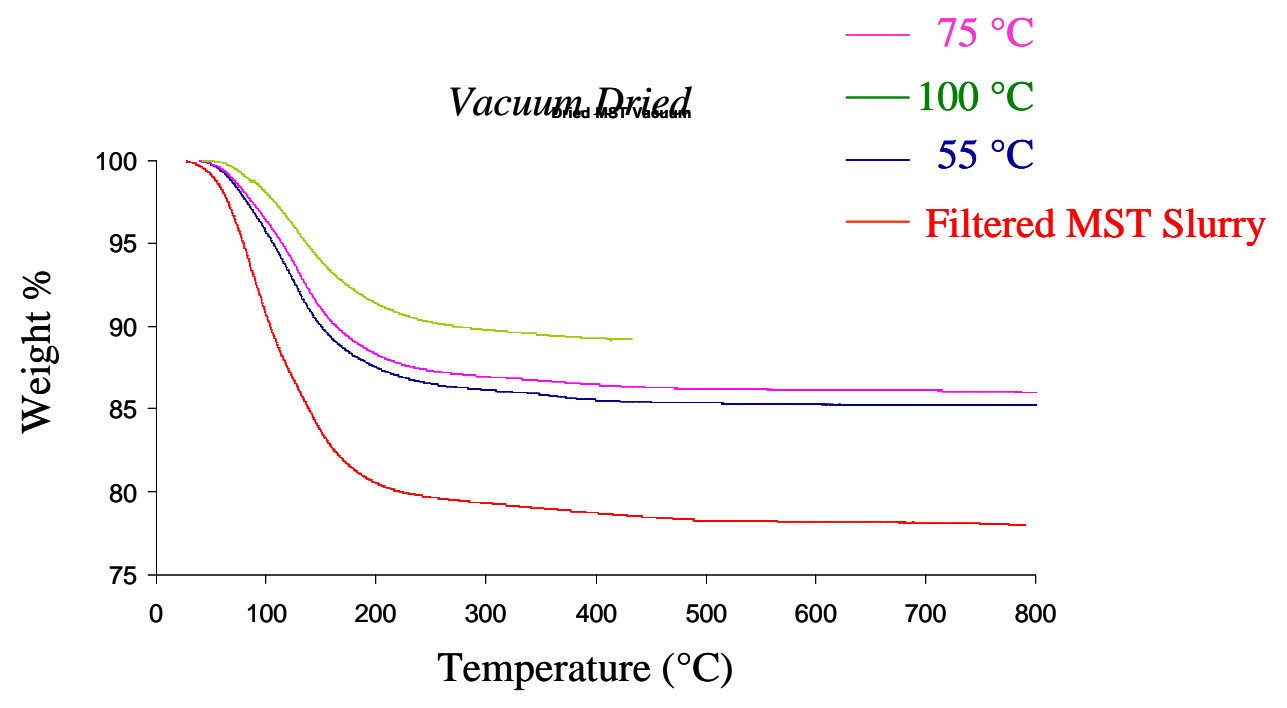

Air Dried

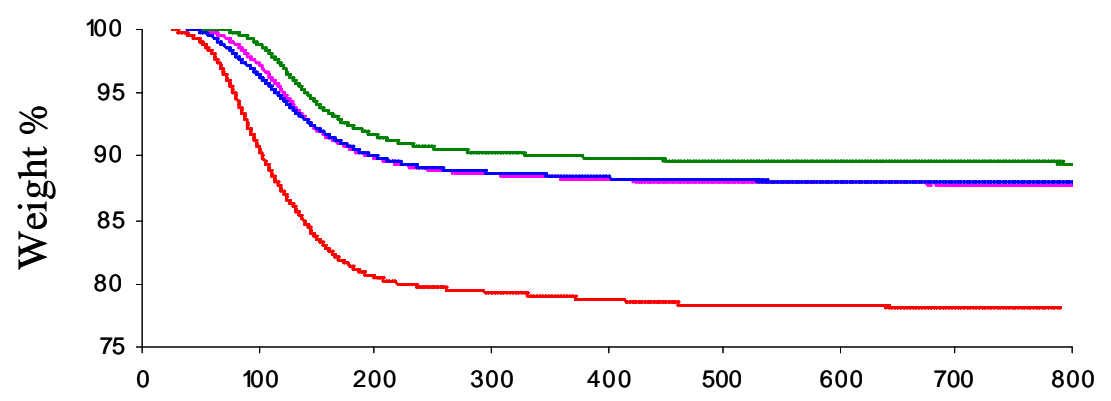

Temperature $\left({ }^{\circ} \mathrm{C}\right)$

Figure 4. X-ray Diffraction Patterns of Representative Dried MST Samples

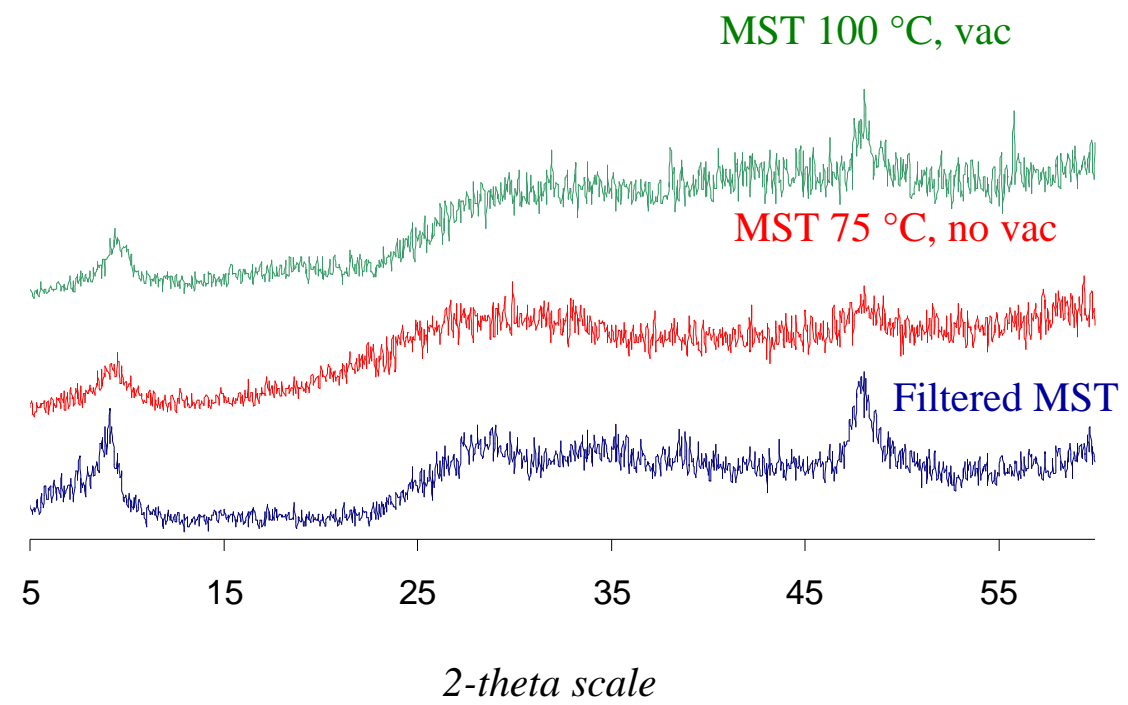


The X-ray diffraction spectra (Figure 4) of all the filtered MST and all dried MST samples (with or without vacuum) show poorly crystalline, layered material with an (001) d-spacing of $\sim 9.5 \AA$. The degree of crystallinity does not change significantly upon drying as observed on the in X-ray powder patterns.

Figure 5 shows TEM microtome slices of MST prepared and vacuum-dried at $100{ }^{\circ} \mathrm{C}$ as described above in section 3.2.1. These TEM images look quite similar previously reported results with MST particles dried in air at ambient temperature. ${ }^{8}$ There is a denser, more brittle core with a rim made up of fibrous material. The layered structure is observed in both the core and the rim material, but the layers have more long-range continuity in the rim material. The rim is $\sim 500 \mathrm{~nm}$ thick and the entire particle is around $1-4$ microns in diameter. The d-spacing of the rim material is slightly larger than that of the core material by about $0.5 \AA$. Again, this could be due to dehydration (as a result of the drying treatment) of the layers that are more external to the particle.

\section{Figure 5. TEM Images of Microtome Sections of MST Dried at $100{ }^{\circ} \mathrm{C}$ in Vacuum \\ A. Showing spherical MST particle morphology with fibrous rim \\ B. HRTEM of the denser core region of the MST particle}
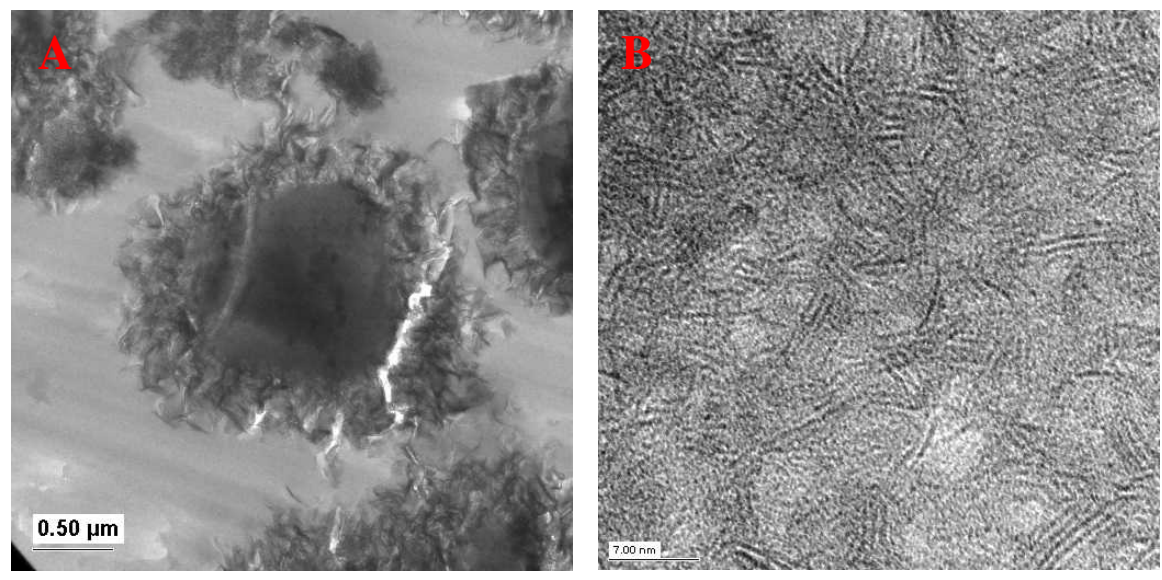

We tested the Sr sorption capabilities of the six dried MST samples using $\sim 0.5 \mathrm{ppm} \mathrm{Sr}$ water solution, spiked with $\mathrm{Sr}-85$ for detection by $\gamma$-counting. For this set of studies we did not use the SRS simulant as a matrix for the Sr sorption studies because we were at optimizing our detection of Sr-85. However, the studies suffice to compare the dried samples to each other as a function of drying conditions. This study also allows comparison of the Sr uptake capabilities of the dried samples to that of the as-received MST. Table 4 provides the results. The kinetics of Sr sorption is clearly superior for the as-received MST. The seven samples can be ranked with regard to kinetics of Sr uptake as follows: as-received MST $>100{ }^{\circ} \mathrm{C}$, vacuum $>75^{\circ} \mathrm{C}$, vacuum $>55^{\circ} \mathrm{C}$, vacuum $>55$ ${ }^{\circ} \mathrm{C}$, air $>75^{\circ} \mathrm{C}$, air $>100{ }^{\circ} \mathrm{C}$, air. No morphological feature in the SEM or TEM images correlates with this observed trend. 
Table 4. Uptake of ${ }^{85} \mathrm{Sr}$ by Dried MST*

\begin{tabular}{|c|c|c|c|c|c|c|}
\hline$\frac{\text { Sample }}{\text { Control }}$ & $\begin{array}{c}\text { 4-h } \gamma \text {-Activity } \\
\frac{(\text { pCi/mL) }}{5.67 \mathrm{E}+03}\end{array}$ & $\begin{array}{c}\begin{array}{c}\text { 2-sigma } \\
(\mathbf{p C i} / \mathbf{m L})\end{array} \\
7.70 \mathrm{E}+02\end{array}$ & $\begin{array}{c}\begin{array}{c}\text { MDL } \\
(\mathbf{p C i} / \mathbf{m L})\end{array} \\
1.42 \mathrm{E}+02\end{array}$ & $\begin{array}{c}\text { 24-h } \gamma \text {-Activity } \\
\frac{(\text { pCi/mL) }}{5.33 \mathrm{E}+03}\end{array}$ & $\begin{array}{c}\begin{array}{c}\text { 2-sigma } \\
(\mathbf{p C i} / \mathbf{m L})\end{array} \\
7.24 \mathrm{E}+02\end{array}$ & $\frac{\begin{array}{c}\text { MDL } \\
(\mathbf{p C i} / \mathbf{m L})\end{array}}{1.10 \mathrm{E}+02}$ \\
\hline MST Slurry & nd & - & $6.90 \mathrm{E}+01$ & nd & - & $6.94 \mathrm{E}+01$ \\
\hline Air Dried $/ 55^{\circ} \mathrm{C}$ & $1.36 \mathrm{E}+03$ & $2.18 \mathrm{E}+02$ & $7.96 \mathrm{E}+01$ & nd & - & $1.71 \mathrm{E}+02$ \\
\hline Air Dried $/ 75^{\circ} \mathrm{C}$ & $1.01 \mathrm{E}+03$ & $1.74 \mathrm{E}+02$ & $8.20 \mathrm{E}+01$ & $3.77 \mathrm{E}+02$ & $9.33 \mathrm{E}+01$ & $8.28 \mathrm{E}+01$ \\
\hline Air Dried $/ 100{ }^{\circ} \mathrm{C}$ & $1.63 \mathrm{E}+03$ & $2.53 \mathrm{E}+02$ & $8.62 \mathrm{E}+01$ & $8.10 \mathrm{E}+02$ & $1.51 \mathrm{E}+02$ & $9.42 \mathrm{E}+01$ \\
\hline Vacuum Dried $/ 55^{\circ} \mathrm{C}$ & $1.26 \mathrm{E}+03$ & $2.04 \mathrm{E}+02$ & $8.24 \mathrm{E}+01$ & nd & - & $9.38 \mathrm{E}+01$ \\
\hline Vacuum Dried $/ 75^{\circ} \mathrm{C}$ & $9.23 \mathrm{E}+02$ & $1.61 \mathrm{E}+02$ & $7.42 \mathrm{E}+01$ & nd & - & $1.32 \mathrm{E}+02$ \\
\hline Vacuum Dried $/ 100^{\circ} \mathrm{C}$ & $4.51 \mathrm{E}+02$ & $4.51 \mathrm{E}+02$ & $8.06 \mathrm{E}+01$ & nd & - & $8.94 \mathrm{E}+01$ \\
\hline
\end{tabular}

*preliminary screening tests conducted with a solution of deionized water containing $\sim 0.5$ ppm stable strontium spiked with ${ }^{85} \mathrm{Sr}$. Testing consisted of contacting $30-\mathrm{mL}$ of solution with $0.012 \mathrm{~g}$ of sorbent at ambient laboratory termperature. Personnel sampled each test bottle after 4 and 24 hours of contact, filtered each sample immediately to remove all solid MST particles and measured $\gamma$-activity in the filtrate. nd $=$ none detected (i.e., below minimum detection level (MDL))

SNL shipped subsamples of the dried MST materials to SRTC for evaluation of combined strontium and actinide removal performance. This testing featured a simulated waste solution previously prepared for MST performance testing in support of the Salt Procesing Project. ${ }^{9}$ Table 3 provides the composition of the simulated waste solution used in this testing.

Sorption results indicate that drying MST did not significantly affect the capacity of the MST for strontium and alpha removal, but did affect removal kinetics. Figures 6 and 7 present plots featuring strontium concentration and alpha activity versus time with the asreceived and dried MST solids. Faster removal of strontium and alpha activity occurs with the as-received MST sample (c.f. 4-h and 24-h values in Figures 6 and 7). After 168 hours of contact, the solution concentrations indicate no significant differences in strontium and alpha activity the possible exception of the samples dried at $100 \mathrm{C}$ with respect to strontium removal.

Based on these results we conclude that drying MST at $55-100{ }^{\circ} \mathrm{C}$, either at atmospheric pressure or reduced pressure, for 4 hours does not alter particle morphology and MST capacity, but does alter the material with respect to removal kinetics. This kinetic effect may be due to dehydration within layers of the monosodium titanate, which reduces the mobility of sodium from sorption sites. We speculate that longer drying times would enhance this effect. Since dried MST materials exhibit poorer removal kinetics compared to the as-received material we recommend not using dry MST in the SWPF or ARP. 
Figure 6. Strontium Removal with As-Received and Dried MST Samples

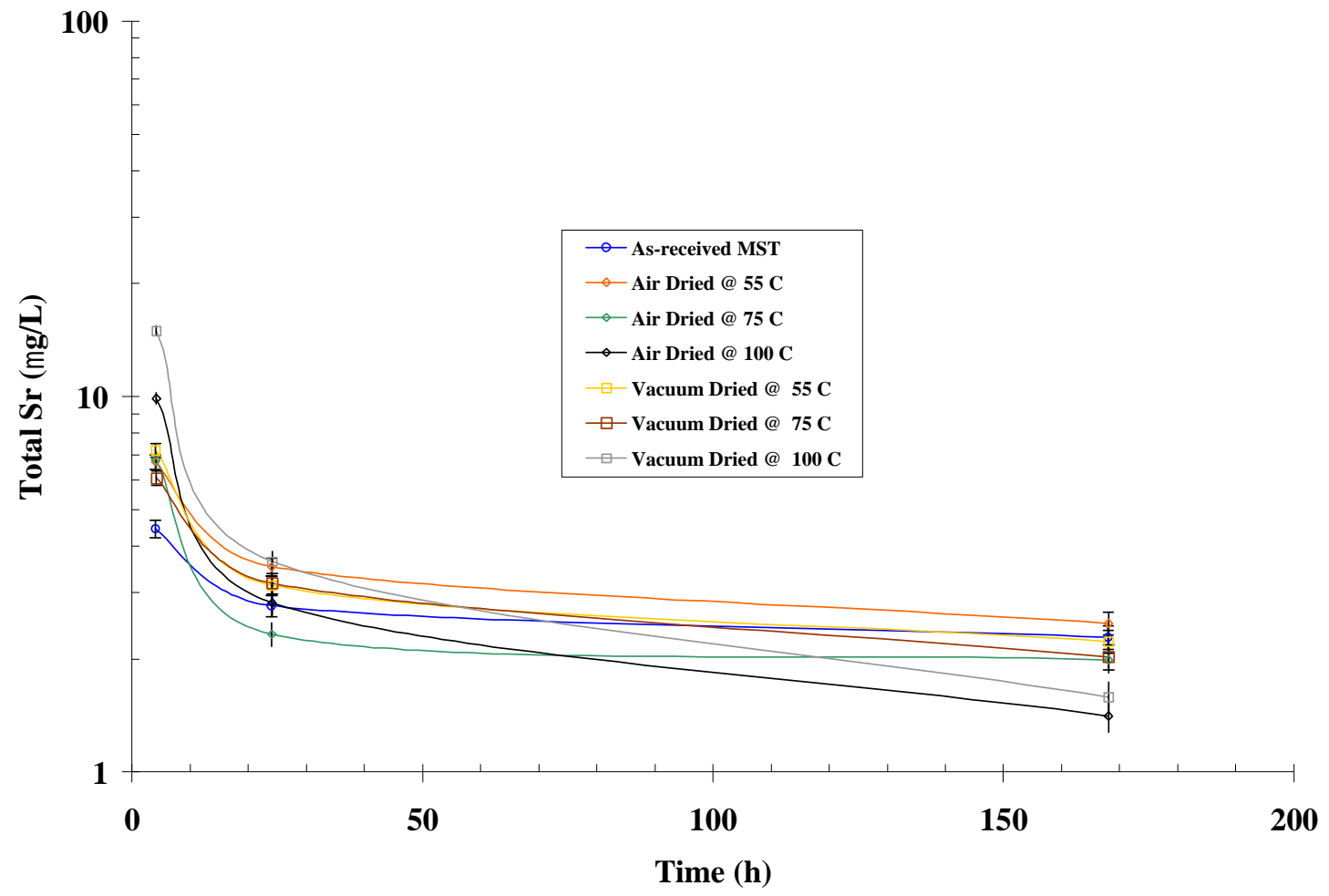

Figure 7. Total Alpha Removal with As-Received and Dried MST Samples

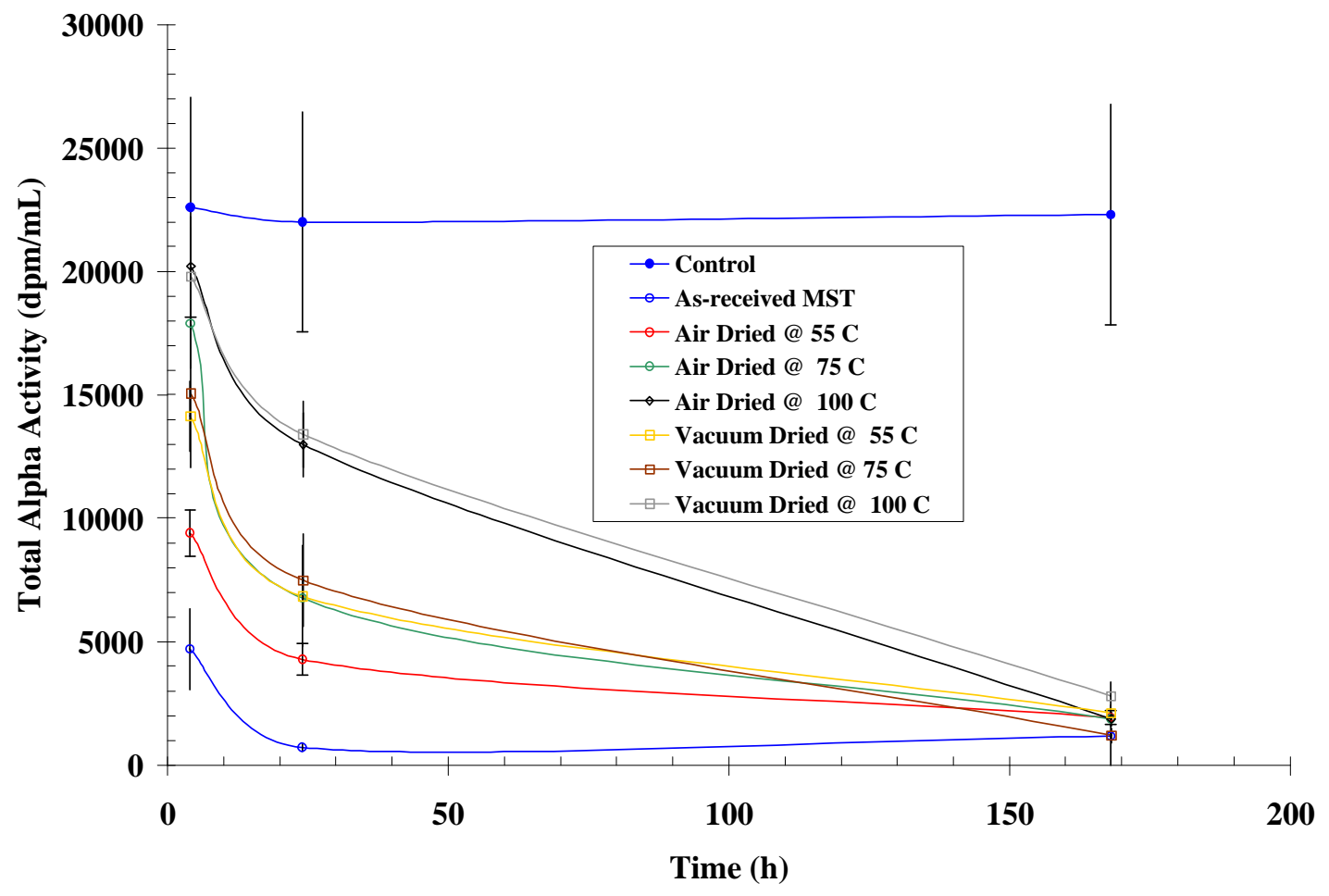




\subsection{Conclusions}

Savannah River Site experience with handling dry solids indicates that handling dried MST within the SWPF or ARP is feasible and could offer certain advantages if the dried material performed equivalently. This evaluation did not identify an operational reason that overwhelmingly supports introducing MST into the SWPF in either a slurry or dry chemical form. Current configuration of the ARP limits introduction of the MST only as a slurry form into the alpha sorption tank. However, testing indicates that dried MST exhibits poorer strontium and alpha removal kinetics, which may adversely impact process cycle times and waste feed throughput. Thus, we recommend that these facilities not use dried MST.

\subsection{Acknowledgements}

The authors thank R. Hopkins, D. Hutsell, and J. Occiphiniti for technical and operational information with regards to solids handling in the DWPF and S. Shah for detailed information concerning the ARP Facility in 512-S. We thank M. S. Blume and H. L. Thacker for their experimental assistance with evaluating the dried MST samples at the SRTC. 
This page was intentionally left blank 


\subsection{References}

${ }^{1}$ Lynch, R. W.; Dosch, R. G.; Kenna, B. T.; Johnstone, J. K.; Nowak, E. J.; Sandia Solification Process: A Broad Range Aqueous Waste Solidification Method. In Management of Radioactive Wastes from the Nuclear Fuel Cycle, Vol., IAEA Symposium on the Management of Radioactive Waste, Vienna, Austria, March 22, 1976, IAEA, Vienna, 1976, p 360-372.

2 Lynch, R. W.; Sandia Solidification Process - Cumulative Report July 1974 - January 1976; Technical Report Sandia National Laboratory, SAND-76-0105, Albuquerque, NM, January 1976.

3 Walker, D. D. and Schmitz, M. A., "Technical Data Summary In-Tank Precipitation Processing of Soluble High-Level Waste,” DPSTD-84-103, May 19884.

${ }^{4}$ Record of Decision: Savannah River Site Salt Processing Alternatives (Salt Processing SEIS, DOE/EIS0082-S2), Federal Register, Vol. 66, No. 201, October 17, 2001.

5 "Actinide Removal Process Alternative Study and Selection (U)," G-ADS-G-00007, Rev. 0, January 2002.

${ }^{6}$ Harris, J. B., "Specification for Procurement of Monosodium Titanate," Specification No. Z-SPP-H00001, Rev. 2, May 1992.

${ }^{7}$ Hobbs, D. T., Nyman, M. and Clearfield, A., "Tailoring Inorganic Sorbents for SRS Strontium and Actinide Separations: Optimized Monosodium Titanate and Pharmacosiderite," Volume 1 - Technical Proposal, WSRC-SRTC-PR-02-21-02, February 7, 2003.

8 Dietz, N. L., Fortner, J. A., Dai, Z., Bradley, J. P., Duff, M. C., Hobbs, D. T. and Fink, S. D., "Transmission Electron Microscopy Analyses of Strontium and Actinide-Bearing Monosodium Titanate and Permanganate Treatment Solids," WSRC-TR-2002-00363, Rev. 0, September 19, 2002.

9 Barnes, M. J., Edwards, T. B., Hobbs, D. T. and Marshall, K. M., "Strontium and Actinide Removal Testing with Monosodium Titanate and Other Sorbents," WSRC-TR-2001-00436, Revision 0, October 29, 2001. 